\title{
Risk management and market structures in seaport-dry port systems
}

\author{
Bi Wang $^{1,2} \cdot$ Kwai Sang $\mathrm{Chin}^{2} \cdot$ Qin Su ${ }^{1}$
}

Accepted: 6 October 2021 / Published online: 18 October 2021

(c) The Author(s), under exclusive licence to Springer Nature Limited 2021

\begin{abstract}
As seaborne and inland transport hubs, seaports and dry ports are vulnerable to diversified risks, such as climate-change-related disasters and congestion in daily operations, owing to their special geographical locations and socioeconomic functions in seaborne supply chains. If appropriate investments are made before the risks occur, the probability and potential damage of such risks can be mitigated. We propose a two-stage game to simultaneously study the preventive and adaptive investments of seaport and dry port authorities on diversified risks in scenarios of vertical cooperation and horizontal competition. In addition, in the latter case, the asymmetry between seaports and dry ports, regarding their vulnerability to risks, is taken into account. Findings show that it is not always advisable to pursue close cooperation, as players in a horizontal relationship must consider not only their own vulnerabilities but also those of others when making investment decisions. Finally, we find that port authorities need to pay more attention to the free-riding problem in the process of preventive investments than in adaptive investments.
\end{abstract}

Keywords Port prevention and adaptation - Peer effect - Competition effect . Vertical cooperation $\cdot$ Horizontal competition $\cdot$ Seaport-dry port system

\section{Introduction}

Recent decades have witnessed the rapid development of international seaborne trade, which has become the backbone of the manufacturing supply chains. At present, more than four-fifths of the world's trade is carried by sea, and the total

Qin Su

qinsu@mail.xjtu.edu.cn

1 School of Management, State Key Laboratory for Manufacturing Systems Engineering, The Key Laboratory of the Ministry of Education for Process Control \& Efficiency Engineering, Xi' an Jiaotong University, Xi'an, China

2 Department of Advanced Design and Systems Engineering, City University of Hong Kong, Hong Kong, China 
seaborne trade reached 11.08 billion tons in 2019 (UNCTAD 2020). However, the rapid development of seaborne trade has exacerbated congestion of seaports. Congestion derives primarily from the connection between seaports and the hinterland; it increases the operating costs of seaports and reduces the efficiency of transits to the hinterland. To relieve seaport congestion and improve logistics solutions for shippers in the hinterland, dry ports have emerged as inland multimodal transport terminals directly connected to seaports by rail or road where shippers can enjoy the same functional requirements as in seaports (Roso et al. 2009; Khaslavskaya and Roso 2020). The inland dry port and the seaport together constitute a seaport-dry port system (Jeevan et al. 2019), such as the Gothenburg seaport and Hallsberg dry port, where the seaport and dry port jointly meet the needs of shippers in the common hinterland (Qiu et al. 2015).

Due to its special strategic location and critical socioeconomic functions, the seaport-dry port system exhibits vulnerabilities to unexpected risks from the sea side and land side, which induce severe economic losses to shippers and society (Chen et al. 2017; Cao and Lam 2019). Depending on the uncertainty of unexpected risks, sources of risk can be divided into disruption events and regular events ( $\mathrm{Li}$ et al. 2016; Lee and Song 2017). For disruption events, existing research has shown that the seaport-dry port system is vulnerable to climate-change-related natural disasters (Gou and Lam 2019; Randrianarisoa et al. 2020). For example, Hurricane Harvey caused a landfall in Louisiana in 2017, leading to the closure of the ports of Houston and Corpus Christi, which resulted in an estimated economic loss of US\$ 125 billion (Lam et al. 2017). Such a risk, which has a low probability of occurrence but causes serious damage, is known as a disruption risk (Lam and Su 2015; Zhang and Lam 2015). For regular events, with the consolidation of liner companies and increased vessel sizes, the capacity of ports ${ }^{1}$ to handle cargo cannot fully meet all liner company requirements, so congestion often occurs (Fan et al. 2012). It has been reported that less than half of containerships arrive at ports on time (Bloomberg 2011). This increases the operating costs of ports and prevents shippers from delivering goods on schedule. Such a risk, which has a high probability of occurrence but causes less damage, is called a regular risk (Kleindorfer and Saad 2005; Li et al. 2016). Because ports play important roles in global trade, interruptions in port services may have knock-on effects on global supply chain performance and the national economy (UNCTAD 2018). Both disruption risk and regular risk affect not only the ports but also trade and regional economic development of the whole seaport-dry port system, so it is vital to control the probability and damage caused by such risks.

To reduce the probability of regular risk and mitigate the potential damage caused by disruption risk, port authorities (PAs) around the world have seriously considered controlling risks through targeted investments (Randrianarisoa et al. 2020). For example, to cope with the congestion caused by coronavirus disease 2019 (COVID19), the Transnet National Port Authority, which is responsible for the management and operation of major ports in South Africa, chose the port of Durban as a pilot project to invest in intelligence and automation, aiming to reduce the probability

\footnotetext{
${ }^{1}$ Hereafter we use "ports" to mean "seaport and dry port."
} 
of congestion. Another pilot project, completed by the Hamburg Port Authority in 2020 , sought to reduce tidal range and storm surge damage by investing in river improvements. At present, there is no shortage of research seeking to develop effective measures to prevent or mitigate risks faced by ports. However, the existing studies are dominated by adaptation to climate-change-related disruption risks (Xiao et al. 2015; Wang et al. 2020). Academic work considering both the prevention of regular risk and the adaptation of disruption risk is relatively rare, however. The regular and disruption risks, respectively, affect the normal operation of the port in terms of high occurrence probability and potential damage, which correspond to two elements of risk. In practice, it is the combination of the two risks that determines the specific measures for risk management ( $\mathrm{Li}$ et al. 2016). To address regular risk, PAs can expand berths and increase cargohandling facilities, thereby reducing the probability of risk occurrence, which is called preventive investment (Liu et al. 2018; Asadabadi and Miller-Hooks 2018). To address disruption risk, PAs can enhance automation, improve drainage facilities, and build storm barriers, aiming to reduce the potential damage caused by climate-change-related natural disasters. For example, Gulfport in Mississippi planned to elevate the entire port (including quays, etc.) from 10 to 25 feet above sea level, to increase risk adaptation capability, which would reduce the damage that the Gulfport could suffer from a future storm surge (Becker et al. 2015). This type of risk (tsunami, typhoon, etc.) is sudden, the probability of such risk cannot be reduced, and only the potential damage caused by it can be reduced through investments, known as adaptive investments (Wang et al. 2020). Both prevention and adaptation are measures taken by PAs to control multiple risks before they occur. Preventive investment is intended to prevent regular risk by reducing the probability of risk occurrence, and adaptive investment is designed to adapt to disruption risk by reducing the possible damage caused by such a risk. Therefore, this research simultaneously studies both types of investment.

In addition to the diversity of risks, preventive and adaptive investments are also heavily affected by the economic relationships of the seaport-dry port system. Owing to the special geographic and strategic location of dry ports, the complex economic relationships of cooperation and competition between seaports and dry ports have been demonstrated (Jackson and Zenou 2015; Gong and Liu 2020). In commercially cooperative relationships, seaports and dry ports are regarded as strategic alliances. Goods are assembled in a dry port and then transported to their destination through the seaport. Seaports and dry ports that exhibit such a relationship belong to our vertical cooperation typology. For example, through combined transport (rail-sea), goods from the dry port of Liege in Belgium are first transported by rail to the port of Antwerp and then exported by sea. The relationship between the dry port of Liege and the seaport of Antwerp entails vertical cooperation of upstream and downstream (Fig. 1). A cooperative relationship will affect negatively the investment enthusiasm of the port authority, which is known as the peer effect or free-riding phenomenon. Such an effect can be explained by the complementary influence of Bonacich centrality (CIBC), where a larger CIBC value means that the player works more closely with the other players in the system, making it easier for the players to steal the investment results of the business partner and reduce their own investment enthusiasm (Chen et al. 2018). Chengdu dry port and Shanghai 


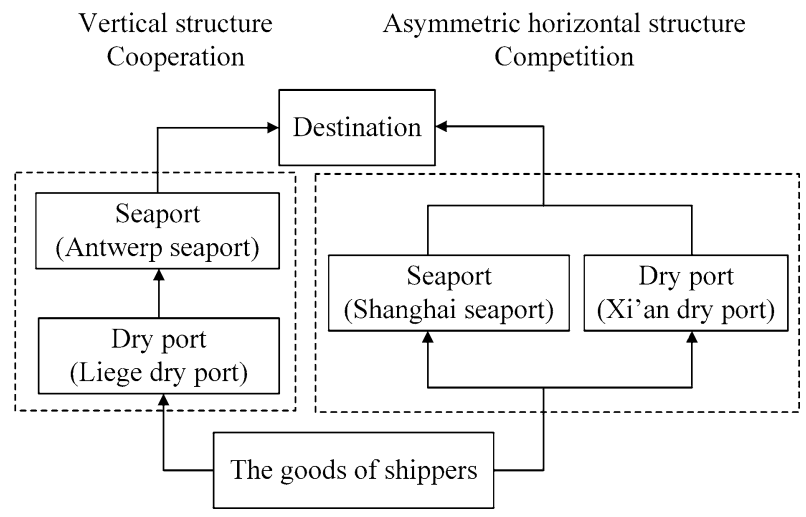

Fig. 1 The economic relationships of the seaport-dry port system

seaport, for example, in the Yangtze River Economic Belt, show cooperative relationships. Being located in the upper and lower reaches of the Yangtze River Basin, the infrastructure investment of the Chengdu dry port can effectively ease the congestion caused by the transit of inland container cargo at the Shanghai seaport. As a result, capacity investment at the Chengdu dry port could dampen the enthusiasm of the Shanghai seaport for investment to ease congestion (free-rider problem).

In a competitive commercial relationship, the seaport and dry port operate independently as substitutes, which is often referred to as horizontal competition (Grauberger and Kimms 2016; Tan et al. 2018) (Fig. 1). For instance, the Belt and Road Initiative has freed Chinese mainland dry ports (e.g., Xi' an dry port, Zhengzhou dry port, Chengdu dry port) from their hinterland role and enabled them to function as (sea)ports with the help of the China Railway Express (CR Express) (Wei et al. 2018). Goods can be transferred from dry ports to Europe by CR Express, which has increased competition between seaports and dry ports, especially in agriculture, fisheries, medicine, and other time-sensitive products. Dry ports have a significant competitive advantage in terms of transport time. The National Development and Reform Commission of China stated at a press conference on 19 January 2021 that, facing the severe impact of the epidemic, dry ports take advantage of their unique advantages through the CR Express, having handled 1.135 million TEUs of cargo throughout the year of 2020 (Agency 2021). This competitive relationship will positively affect the investment enthusiasm of the PA, known as the competition effect (Wang and Zhang 2018). Moreover, different from previous studies on two seaports that are assumed to exhibit the same vulnerability to risk (Randrianarisoa and Zhang 2019; Wang and Zhang 2018), an asymmetric seaport-dry port system is studied here, whereby asymmetry should be understood as the different vulnerabilities to risk of seaports and dry ports. For example, seaports are more sensitive to disruption risk, and dry ports are more sensitive to regular risk owing to their unique geographic locations. To the best of our knowledge, there is a gap in the literature regarding the impact of vertical cooperation and horizontal competition on preventive and adaptive investments, with regard to the peer effect and competition effect. 
Therefore, this study proposes a two-stage game model to investigate the preventive and adaptive investment decisions of the seaport and dry port authorities under diverse risks in vertical cooperation and asymmetric horizontal competition while considering the peer and competition effects. Specifically, at the strategic stage, cooperative or competitive seaport and dry port authorities make adaptive or preventive investment decisions regarding disruption and regular risks, respectively. At the operational stage, the pricing decisions are made based on the investment decisions in the first stage. This study is organized as follows. The next section reviews previous studies on the investment decisions of PAs and the structure of the seaborne supply chain. Section 3 establishes the basic model for the seaport-dry port system. Section 4 derives the analytical results for equilibrium preventive and adaptive investment under diverse risks. Finally, conclusions and future research directions are given in Sect. 5.

\section{Literature review}

This study mainly involves two research streams. The first focuses on the targeted investment decisions of PAs, while the second is primarily concerned with the impact of complex commercial relationships between players on investment decisions.

\subsection{Targeted investment decisions of PAs}

Due to the diversity of risks faced by seaborne supply chains, many scholars have studied the investment decisions of PAs in response to climate-change-related natural disasters. Xiao et al. (2015) developed an economic model to study preventive investment, to address seaborne disasters, simultaneously considering uncertain risk occurrence probability and return on investment. Wang and Zhang (2018) extended Xiao et al. (2015) assumption that the probability of risk occurrence is uniformly distributed, in a model that can be characterized by a general distribution. They found that the uncertainty in the probability of risk occurrence and the co-opetition between ports had impacts on adaptive investment decisions. Randrianarisoa and Zhang (2019) constructed a real options game model to investigate the optimal investment time and scale of competitive ports, to address climate change under uncertain investment efficiency. However, these studies all emphasize the effect of adaptative investments on climate-change-related disruption risk. There is a lack of research on preventive investment for regular risk of a high probability of occurrence. Gong and Liu (2020) examined mitigating investments, to minimize the probability of the occurrence of a disaster in a seaport-dry port system, treating port pricing as exogenous to investments. However, the investment decisions of a port will affect its competitive advantage, so it is important to endogenize the pricing decision in the operational stage. As a result, we not only analyze preventive investment for regular risk and adaptive investment for disruption risk in the strategic stage but also consider the pricing decision in the operational stage. 


\subsection{The impact of the commercial relationship of players on their investment decisions}

Due to their specific location and socioeconomic functions, seaborne supply chains exhibit complicated economic relationships (Zheng and Luo 2021), which can affect the scale and effectiveness of port investment in risk prevention and adaptation. Traditionally, economic relationships between ports in the seaborne supply chain have been expressed as vertical cooperation (Lam and Yap 2011; Irannezhad et al. 2018) and horizontal competition (Song et al. 2016; Zhang et al. 2018). However, our study differs from prior work in that, in the process of risk prevention and adaptation, vertical cooperation is understood when the investment of one player affects negatively the investment enthusiasm of other players in the system; i.e., our peer effect. Chen et al. (2018) described the cooperative relationships in a multimodal transport network, based on network game theory, and showed that the peer effect suppresses risk-prevention investment. In addition, horizontal competition is manifested by the investment of one player positively affecting the investment enthusiasm of others in the system: our competition effect. Wang and Zhang (2018) investigated the adaptative investment of two competing ports and demonstrated that the competition effect promotes the investments of PAs. Unlike most existing studies that focus on two symmetric seaports that are assumed to exhibit the same vulnerability to risk (Liu et al. 2018; Randrianarisoa and Zhang 2019), this study analyzes the impact of peer and competition effects of an asymmetric seaport-dry port system on prevention and adaptation. In addition to asymmetric geographic locations, asymmetry is also understood by the asymmetric vulnerability of seaports and dry ports to risks. For example, seaports are more sensitive to disruption risk, and dry ports are more sensitive to regular risk owing to their unique geographic locations.

Among the above review, we find some unresolved issues in the field of risk prevention and adaptation of seaport-dry port systems. How do vertically cooperative and horizontally competitive seaports and dry ports make optimal preventive and adaptive investments to address regular and disruption risks under the peer and competition effects? How does the uncertain vulnerability caused by risk diversity affect the peer effect and the competition effect, thereby affecting the investment decisions of seaports and dry ports? How does the asymmetry affect preventive and adaptive investments in seaports and dry ports? Hence, in this study, a two-stage game is used to model strategic investment decisions for seaports and dry ports under cooperative and substitutive commercial relationships that simultaneously considers risk diversity, the peer effect, and the competition effect.

\section{Basic model specifications}

In this study, a seaport and a dry port jointly serve shippers in a common hinterland. The two ports can be cooperative or competitive (Fig. 1). Since the 1990s, port governance has gradually shifted from central government to PAs. Ports are increasingly privatized, and the concept of profit assumes a different dimension (Iannone 2012; Kavirathna et al. 2019). Therefore, a two-stage game model with 


\begin{tabular}{|c|c|c|c|}
\hline \multirow[b]{2}{*}{$\begin{array}{c}\text { Asymmetric } \\
\text { horizontal competition }\end{array}$} & Strategic investment stage & \multicolumn{2}{|c|}{ Operational pricing stage } \\
\hline & $\begin{array}{l}\text { Preventive and adaptive } \\
\text { investments } I_{i}^{p}, I_{i}^{a} \\
\text { are determined }\end{array}$ & $\begin{array}{l}\text { The } \mathrm{THC} f_{l}, f_{s} \text { are } \\
\text { determined by the dry port } \\
\text { and seaport respectively }\end{array}$ & $\begin{array}{l}\text { Shippers choose } \\
\text { seaport or dry port }\end{array}$ \\
\hline $\begin{array}{c}\text { Vertical } \\
\text { cooperation }\end{array}$ & $\begin{array}{l}\text { Preventive and adaptive } \\
\text { investments } I_{i}^{p}, I_{i}^{a} \\
\text { are determined }\end{array}$ & \begin{tabular}{|c|c} 
The seaport & The dry port \\
charges to the & charges to the \\
dry port $f_{s}$ & shippers $f_{l}$
\end{tabular} & $\begin{array}{l}\text { Shipper transports } \\
\text { the goods through } \\
\text { the seaport }\end{array}$ \\
\hline
\end{tabular}

Fig. 2 Decision-making process for the PAs

profit maximization as the decision objective is adopted here, aiming to determine strategic investment and operational pricing (Fig. 2). At the strategic stage, the PA makes preventive and adaptive investment decisions for regular and disruption risks to maximize profit. At the operational stage, the horizontally competitive PAs decide the terminal handling charges (THC) charged to users. In a vertically cooperative partnership, the seaport authority first determines the THC charged to the dry port authority, and then the dry port authority determines the THC charged to port users.

Specifically, at the strategic stage, port $i$ (seaport or dry port authority) determines the preventive investment $I_{i}^{\mathrm{p}}$ or adaptive investment $I_{i}^{\mathrm{a}}$ according to the type of risk, which can mitigate the damage suffered by shippers. The damage suffered by the shippers due to regular or disruption risk at port $i$ is denoted by $D_{i}^{\mathrm{r}}$ and $D_{i}^{\mathrm{d}}$, respectively, $D_{i}^{\mathrm{r}}<D_{i}^{\mathrm{d}}$. The damage is assumed to be directly proportional to the risk occurrence probability $P_{i}^{\mathrm{r}}$ and $P_{i}^{\mathrm{d}}, P_{i}^{\mathrm{r}}>P_{i}^{\mathrm{d}}$ (Xiao et al. 2015). Through preventive investment, the probability of regular risk will be reduced by $F\left(I_{i}^{\mathrm{p}}\right)$, where $F(I)$ is the absorption function of risk (Chen et al. 2018). The risk absorption function is used to describe the degree of absorption of the actual damage caused by the risk after the players take preventive or adaptive investment measures. Specifically, through adaptive investment $I_{i}^{\mathrm{a}}$, the potential damage caused by disruption will be reduced by $F\left(I_{i}^{\mathrm{a}}\right)$. Through preventive investment $I_{i}^{\mathrm{p}}$, the probability of regular risk will be reduced by $F\left(I_{i}^{\mathrm{P}}\right)$. Generally, with an increase in investment, the ability of the absorption function will decrease accordingly, so in this study, a function $F(I)=\alpha \sqrt{I}$ is used to characterize the degree of risk absorption, where $\alpha$ indicates investment efficiency and $I$ represents the amount of investment.

Preventive investment can reduce the probability of regular risk and thus mitigate the damage caused by such risk. Therefore, the reduction in the actual risk damage suffered by port users due to regular risk can be expressed as $D_{i}^{\mathrm{r}} P_{i}^{\mathrm{r}}\left(1-\alpha_{\mathrm{p}} \sqrt{I_{i}^{\mathrm{p}}}\right) \pm \beta \sqrt{I_{j}^{\mathrm{p}}}$, where $\alpha_{\mathrm{p}}$ indicates preventive investment efficiency; $\beta$ indicates the strength of the cooperative or competitive relationship between the two ports; $\alpha_{\mathrm{p}}>\beta>0$. $D_{i}^{\mathrm{r}} P_{i}^{\mathrm{r}}\left(1-\alpha_{\mathrm{p}} \sqrt{I_{i}^{\mathrm{p}}}\right)$ represents the damage suffered by the shippers after the preventive investment is made by port $i$; and $\beta \sqrt{I_{j}^{\mathrm{p}}}$ represents the peer effect or the competition effect between the two ports, indicating the impact of the preventive investment of port $j$ on port $i .-\beta \sqrt{I_{j}^{\mathrm{p}}}$ means that the 
peer effect caused by cooperative commercial relationships will inhibit the investment efficiency of PAs (Chen et al. 2018), whereas $+\beta \sqrt{I_{j}^{\mathrm{p}}}$ means that the competition effect caused by competitive commercial relationships will enhance the investment efficiency of PAs. To better demonstrate the degree to which the actual damage is reduced by the preventive investment, the reduction in the shippers' utility can be converted into $D_{i}^{\mathrm{r}} P_{i}^{\mathrm{r}}-\left(D_{i}^{\mathrm{r}} P_{i}^{\mathrm{r}} \alpha_{\mathrm{p}} \sqrt{I_{i}^{\mathrm{p}}} \pm \beta \sqrt{I_{j}^{\mathrm{p}}}\right)$, where $D_{i}^{\mathrm{r}} P_{i}^{\mathrm{r}} \alpha_{\mathrm{p}} \sqrt{I_{i}^{\mathrm{p}}} \pm \beta \sqrt{I_{j}^{\mathrm{p}}}$ is considered as additional utility enjoyed by the shippers. This additional utility is expressed as "the reduction in the expected regular risk damage of shippers." $D_{i}^{\mathrm{r}} P_{i}^{\mathrm{r}}$ is composed of two dimensions of risk vulnerability, namely risk occurrence probability and damage caused by the risk (Kaplan and Garrick 1981; Berdica 2002), so $D_{i}^{\mathrm{r}} P_{i}^{\mathrm{r}}$ can be used to indicate the vulnerability of port $i$ to regular risk. Since dry ports are generally located in inland multimodal corridors, it is reasonable to assume that the dry port is more sensitive to regular risk (e.g., congestion), that is, $D_{1}^{\mathrm{r}} P_{1}^{\mathrm{r}}>D_{\mathrm{s}}^{\mathrm{r}} P_{\mathrm{s}}^{\mathrm{r}}$.

With respect to disruption risk, the probability of occurrence cannot be reduced through preventive investment owing to the unexpectedness of the risk, but the potential damage caused by it can be reduced through adaptive investment. The reduction in shipper utility can be expressed as $D_{i}^{\mathrm{d}} P_{i}^{\mathrm{d}}-\left(\alpha_{\mathrm{a}} \sqrt{I_{i}^{\mathrm{a}}} \pm \beta \sqrt{I_{j}^{\mathrm{a}}}\right)$, where $D_{i}^{\mathrm{d}} P_{i}^{\mathrm{d}}$ is the actual loss suffered by port $i$, namely the vulnerability of port $i$ to disruption risk. Similar to regular risk, $\alpha_{\mathrm{a}} \sqrt{I_{i}^{\mathrm{a}}} \pm \beta \sqrt{I_{j}^{\mathrm{a}}}$ gives "the reduction in the expected disruption risk damage of shippers," where $\alpha_{a}$ indicates adaptive investment efficiency, $\pm \beta \sqrt{I_{j}^{a}}$ indicates the peer effect or the competition effect, and $\alpha_{\mathrm{a}}>\beta>0$. Seaports are generally located in coastal areas, low-lying areas, and estuaries, which makes them more sensitive to climate-change-related disruption risks such as floods or hurricanes. Therefore, it is reasonable to assume that the vulnerability of the seaport to disruption risk is greater than that of the dry port, namely $D_{1}^{\mathrm{d}} P_{1}^{\mathrm{d}}>D_{\mathrm{s}}^{\mathrm{d}} P_{\mathrm{s}}^{\mathrm{d}}$.

The PAs will make the most suitable investment decision according to their own operational conditions, geographical location, and other factors under their existing resource constraints. Specifically, due to the irreversibility and lumpiness of investments, ports that are vulnerable to climate-change-related risks, such as hurricanes, only make adaptive investments. For example, the low-lying Rotterdam seaport makes adaptive investments to address the risks brought by climate change. In 1954, the port adopted adaptive investment to build its Delta Works to address risks such as floods caused by rising sea levels (Xiao et al. 2015). Ports that are vulnerable to daily operational risks such as congestion only make preventive investments. For example, the Baltimore seaport responded to the risk of congestion, due to increased demand and ship sizes, by making preventive investments in additional berths and giant cranes (Fan et al. 2012). Therefore, it is assumed that, due to the preference for diverse risks, PAs can only make one type of investment decision (preventive investment or adaptive investment). Under the vertical cooperation and asymmetric horizontal competition, the degree of damage absorption for shippers through investments in the seaport and dry port is expressed as in Table 1. 
Table 1 Degree of damage absorption caused by diverse risks

\begin{tabular}{llc}
\hline & Regular risk & Disruption risk \\
\hline Vertical cooperation & $D_{i}^{\mathrm{r}} P_{i}^{\mathrm{r}} \alpha_{\mathrm{p}} \sqrt{I_{\mathrm{i}}^{\mathrm{p}}}-\beta \sqrt{I_{\mathrm{j}}^{\mathrm{p}}}$ & $\alpha_{\mathrm{a}} \sqrt{I_{i}^{\mathrm{a}}}-\beta \sqrt{I_{j}^{\mathrm{a}}}$ \\
$\begin{array}{l}\text { Asymmetric horizontal } \\
\text { competition }\end{array}$ & $D_{i}^{\mathrm{r}} P_{i}^{\mathrm{r}} \alpha_{\mathrm{p}} \sqrt{I_{i}^{\mathrm{p}}}+\beta \sqrt{I_{j}^{\mathrm{p}}}$ & $\alpha_{\mathrm{a}} \sqrt{I_{i}^{\mathrm{a}}}+\beta \sqrt{I_{j}^{\mathrm{a}}}$ \\
\hline
\end{tabular}

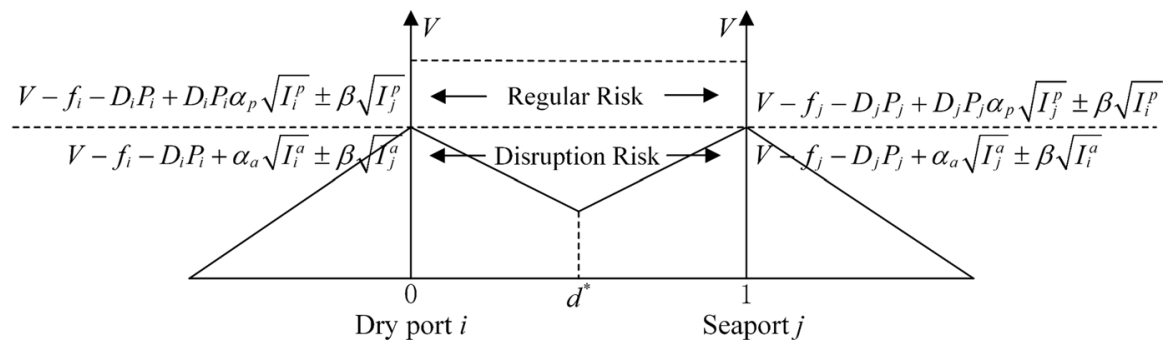

Fig. 3 Utility of shippers along the linear city model

At the operational stage, in the vertically cooperative relationship, the seaport authority first decides the THC $f_{\mathrm{s}}$ charged to the dry port, and then the dry port authority charges their THC $f_{1}$ to shippers. It is assumed that the seaport-dry port system is a strategic alliance, which is vertically integrated. As a result, the THC charged by the seaport to the dry port can be regarded as exogenous, not affecting the investment decisions of the ports. In the asymmetric horizontal competition, shippers choose between the seaport and the dry port, and then the seaport or the dry port directly transports handles the goods to their destination. For example, the Qingdao seaport ships goods to Europe by sea, and the Xi'an dry port transports goods to Europe through the CR Express.

Following Wang and Zhang (2018), the linear city model is used to obtain the demand $Q_{i}$ for the seaport and dry port (Fig. 3). Assume that the shippers are uniformly distributed in the common hinterland (between 0 and 1) of the seaport and dry port, with density 1 . For a shipper located at $d$, the net utility of choosing port $i$ can be expressed as $V-f_{i}-\mathrm{d} c-D_{i} P_{i}+D_{i} P_{i} \alpha_{\mathrm{p}} \sqrt{I_{i}^{\mathrm{p}}} \pm \beta \sqrt{I_{j}^{\mathrm{p}}}$ for regular risk, or $V-f_{i}-\mathrm{d} c-D_{i} P_{i}+\alpha_{\mathrm{a}} \sqrt{I_{i}^{\mathrm{a}}} \pm \beta \sqrt{I_{j}^{\mathrm{a}}}$ for disruption risk. The net utility of choosing port $j$ can be expressed as $V-f_{j}-(1-\mathrm{d}) c-D_{j} P_{j}+D_{j} P_{j} \alpha_{\mathrm{p}} \sqrt{I_{j}^{\mathrm{p}}} \pm \beta \sqrt{I_{i}^{\mathrm{p}}}$ for regular risk, or $V-f_{j}-(1-\mathrm{d}) c-D_{j} P_{j}+\alpha_{\mathrm{a}} \sqrt{I_{j}^{\mathrm{a}}} \pm \beta \sqrt{I_{i}^{\mathrm{a}}}$ for disruption risk, where $V$ indicates the total utility of the shipper, $d$ refers to the distance between the location of shippers and the port, and $c$ corresponds to the transportation cost per unit of distance. It can be inferred that the location of the indifferent shipper is $d^{*}=\left[c+f_{j}-f_{i}+D_{j} P_{j}-D_{i} P_{i}+\left(D_{i} P_{i} \alpha_{\mathrm{p}} \pm \beta\right) \sqrt{I_{i}^{\mathrm{p}}-\left(D_{j} P_{j} \alpha_{\mathrm{p}} \pm \beta\right) \sqrt{I_{j}^{\mathrm{p}}}}\right] /(2 c)$ for regular risk or $d^{*}=\left[c+f_{j}-f_{i}+D_{j} P_{j}-D_{i} P_{i}+\left(\alpha_{\mathrm{a}} \pm \beta\right) \sqrt{I_{i}^{\mathrm{a}}}-\left(\alpha_{\mathrm{a}} \pm \beta\right) \sqrt{I_{j}^{\mathrm{a}}}\right] /(2 c)$ 
Table 2 Notational glossary

\begin{tabular}{ll}
\hline Parameter & Definition \\
\hline$D_{i}^{\mathrm{r}}, D_{i}^{\mathrm{d}}$ & Damage to shipper due to regular and disruption risks at port $i$ \\
$P_{i}^{\mathrm{r}}, P_{i}^{\mathrm{d}}$ & Probability of regular and disruption risks at port $i$ \\
$I_{i}^{\mathrm{p}},,_{i}^{a}$ & Preventive and adaptive investment at port $i$ \\
$F(I)$ & Degree of risk absorption from investment $I$ \\
$\alpha_{\mathrm{p}}, \alpha_{\mathrm{a}}$ & Investment efficiency of preventive and adaptive investment \\
$\beta$ & Strength of commercial relations between seaport and dry port \\
$U$ & Net utility of the shippers \\
$V$ & Total utility to shippers from using the port service \\
$f_{i}$ & THC charged by port $i$ \\
$c$ & Transport cost per unit distance \\
$Q_{i}$ & Demand for port $i$ \\
$\pi_{i}$ & Profit of port $i$ \\
\hline
\end{tabular}

for disruption risk. Because shippers are assumed to be uniformly distributed in a linear city model with density 1 , the demand for port services at the operational stage can be represented as $Q_{i}=d^{*}, Q_{j}=1-Q_{i}$. Table 2 summarizes the parameter definitions and notations of the study.

\section{Analysis}

In this part, according to the two factors that affect port investment, i.e., risk diversity and economic relations between ports, the research is divided into four scenarios (Table 1). Then, the pricing decision at the operational stage and the investment decision at the strategic stage of the seaport and dry port authorities under different economic relations are elaborated by backward induction.

\subsection{Investment decisions under a vertically cooperative relation}

This section examines the preventive and adaptive investment decisions of vertically cooperative PAs, in which seaport and dry port face regular risk or disruption risk. The cooperative commercial relationship creates the peer effect, which makes the investment of one player negatively affect the investment enthusiasm of the other (Chen et al. 2018).

\subsubsection{Case 1}

In this case, vertically cooperative seaport and dry port authorities make preventive investment to address regular risk. During the operational stage, the net utility of the shipper in transporting the cargo to the dry port can be expressed as 
$V-f_{1}-\mathrm{d} c-D_{1}^{\mathrm{r}} P_{1}^{\mathrm{r}}+D_{1}^{\mathrm{r}} P_{1}^{\mathrm{r}} \alpha_{\mathrm{p}} \sqrt{I_{1}^{\mathrm{p}}}-\beta \sqrt{I_{\mathrm{s}}^{\mathrm{p}}}$. In addition, the demand for the dry port is $Q=d^{*}=\left(V-f_{1}-D_{1}^{\mathrm{r}} P_{1}^{\mathrm{r}}+D_{1}^{\mathrm{r}} P_{1}^{r} \alpha_{\mathrm{p}} \sqrt{I_{1}^{\mathrm{p}}}-\beta \sqrt{I_{\mathrm{s}}^{\mathrm{p}}}\right) / c$. The demand for port services is directly related to "the reduction in the expected regular risk damage of shippers" $D_{1}^{\mathrm{r}} P_{1}^{\mathrm{r}} \alpha_{\mathrm{p}} \sqrt{I_{1}^{\mathrm{p}}}-\beta \sqrt{I_{\mathrm{s}}^{\mathrm{p}}}$, the THC $f_{1}$ and the unit distance transportation cost $c$. Without loss of generality, we assume that the unit operating costs of seaport and dry port authorities do not affect their investment decision and are thus set equal to zero (Wang and Zhang 2018). Therefore, the profit of the dry port and seaport can be expressed as $\pi_{1}=\left(f_{1}-f_{\mathrm{s}}\right) Q-I_{1}^{\mathrm{p}}$ and $\pi_{\mathrm{s}}=f_{\mathrm{s}} Q-I_{\mathrm{s}}^{\mathrm{p}}$, respectively, where $f_{\mathrm{s}}$ is the THC charged by the seaport to the dry port. Since vertically cooperative seaports and dry ports can be regarded as vertically integrated, $f_{\mathrm{s}}$ can be considered exogenous. The objective is to maximize total profit of the PAs, and we obtain:

$$
\pi=\pi_{1}+\pi_{\mathrm{s}}=f_{1} Q-I_{1}^{\mathrm{p}}-I_{\mathrm{s}}^{\mathrm{p}} .
$$

In the operational pricing stage, the preventive investments in the seaport and dry port have been completed. At this time, the dry port authority sets the THC $f_{1}$ charged to shippers so as to maximize total system profit (seaport and dry port together). By solving the first-order conditions, $\partial \pi / \partial f_{1}=0$, the equilibrium THC can be derived as:

$$
f_{1}=\frac{V-D_{1}^{\mathrm{r}} P_{1}^{\mathrm{r}}+D_{1}^{\mathrm{r}} P_{1}^{\mathrm{r}} \alpha_{\mathrm{p}} \sqrt{I_{1}^{\mathrm{p}}}-\beta \sqrt{I_{\mathrm{s}}^{\mathrm{p}}}}{2},
$$

where the second-order condition, $\partial^{2} \pi / \partial f_{1}^{2}<0$, is satisfied. The second-order conditions are verified for all of the following optimal solutions.

In the strategic investment stage, it is assumed that the seaport and dry port authorities simultaneously determine preventive investments to maximize profits. By substituting (2) into (1), we obtain:

$$
\pi=\frac{\left(V-D_{1}^{\mathrm{r}} P_{1}^{\mathrm{r}}+D_{1}^{\mathrm{r}} P_{1}^{\mathrm{r}} \alpha_{\mathrm{p}} \sqrt{I_{1}^{\mathrm{p}}}-\beta \sqrt{I_{\mathrm{s}}^{\mathrm{p}}}\right)^{2}}{4 c}-I_{1}^{\mathrm{p}}-I_{\mathrm{s}}^{\mathrm{p}} .
$$

Solve the first-order conditions, $\partial \pi / \partial I_{1}^{\mathrm{p}}=0, \partial \pi / \partial I_{\mathrm{s}}^{\mathrm{p}}=0$, which jointly derive the following preventive investments:

$$
I_{1}^{\mathrm{p}}=\frac{D_{1}^{\mathrm{r} 2} P_{1}^{\mathrm{r} 2} \alpha_{\mathrm{p}}^{2}\left(V-D_{1}^{\mathrm{r}} P_{1}^{\mathrm{r}}\right)^{2}}{\left(4 c-D_{1}^{\mathrm{r} 2} P_{1}^{\mathrm{r} 2} \alpha_{\mathrm{p}}^{2}-\beta^{2}\right)^{2}} I_{\mathrm{s}}^{\mathrm{p}}=\frac{\beta^{2}\left(V-D_{1}^{\mathrm{r}} P_{1}^{\mathrm{r}}\right)^{2}}{\left(4 c-D_{1}^{\mathrm{r} 2} P_{1}^{\mathrm{r} 2} \alpha_{\mathrm{p}}^{2}-\beta^{2}\right)^{2}} .
$$

By substituting (4) into (2) and (3), we obtain

$$
f_{1}=\frac{\left(2 c-\beta^{2}\right)\left(V-D_{1}^{\mathrm{r}} P_{1}^{\mathrm{r}}\right)}{4 c-D_{1}^{\mathrm{r} 2} P_{1}^{\mathrm{r} 2} \alpha_{\mathrm{p}}^{2}-\beta^{2}}
$$




$$
\pi=\frac{\left(V-D_{1}^{\mathrm{r}} P_{1}^{\mathrm{r}}\right)^{2}\left(D_{1}^{\mathrm{r} 2} P_{1}^{\mathrm{r} 2} \alpha_{\mathrm{p}}^{2} c-\beta^{4}+5 \beta^{2} c-4 c^{2}\right)}{4 c-D_{1}^{\mathrm{r} 2} P_{1}^{\mathrm{r} 2} \alpha_{\mathrm{p}}^{2}-\beta^{2}} .
$$

We can determine how the vulnerability of the dry port $D_{1}^{\mathrm{r}} P_{1}^{\mathrm{r}}$, investment efficiency $\alpha_{\mathrm{p}}$, the intensity of cooperative commercial relationships $\beta$, and unit distance transportation costs $c$ affect the preventive investments of the seaport and dry port. It can be easily seen that:

$$
\frac{\partial I_{1}^{\mathrm{p}}}{\partial \alpha_{\mathrm{p}}}>0, \frac{\partial I_{1}^{\mathrm{p}}}{\partial \beta}>0, \frac{\partial I_{1}^{\mathrm{p}}}{\partial c}<0, \frac{\partial I_{\mathrm{s}}^{\mathrm{p}}}{\partial \alpha_{\mathrm{p}}}>0, \frac{\partial I_{\mathrm{s}}^{\mathrm{p}}}{\partial \beta}>0, \frac{\partial I_{\mathrm{s}}^{\mathrm{p}}}{\partial c}<0 .
$$

Intuitively, high investment efficiency and the strength of the cooperative commercial relationship will promote preventive investment to regular risk, while high unit distance transportation costs will inhibit preventive investment. However, the signs of these two formulas, $\partial I_{1}^{\mathrm{p}} / \partial D_{1}^{\mathrm{r}} P_{1}^{\mathrm{r}}$ and $\partial I_{\mathrm{s}}^{\mathrm{p}} / \partial D_{1}^{\mathrm{r}} P_{1}^{\mathrm{r}}$, are not fixed.

$$
\left\{\begin{array}{l}
\frac{\partial I_{1}^{\mathrm{p}}}{\partial D_{1}^{\mathrm{r}} P_{1}^{\mathrm{r}}}=\frac{2 D_{1}^{\mathrm{r}} P_{1}^{\mathrm{r}} \alpha_{\mathrm{p}}^{2}\left(V-D_{1}^{\mathrm{r}} P_{1}^{\mathrm{r}}\right)\left(V D_{1}^{\mathrm{r} 2} P_{1}^{\mathrm{r}} \alpha_{\mathrm{p}}^{2}+2 D_{1}^{\mathrm{r}} P_{1}^{\mathrm{r}} \beta^{2}-8 c D_{1}^{\mathrm{r}} P_{1}^{\mathrm{r}}+4 V c-V \beta^{2}\right)}{\left(4 c-D_{1}^{\mathrm{r} 2} P_{1}^{\mathrm{r} 2} \alpha_{\mathrm{p}}^{2}-\beta^{2}\right)^{3}} \\
\frac{\partial I_{\mathrm{s}}^{\mathrm{p}}}{\partial D_{1}^{\mathrm{r}} P_{1}^{\mathrm{r}}}=\frac{2 \beta^{2}\left(V-D_{1}^{\mathrm{r}} P_{1}^{\mathrm{r}}\right)\left(-D_{1}^{\mathrm{r} 2} P_{1}^{\mathrm{r} 2} \alpha_{\mathrm{p}}^{2}+2 V D_{1}^{\mathrm{r}} P_{1}^{\mathrm{r}} \alpha_{\mathrm{p}}^{2}-4 c+\beta^{2}\right)}{\left(4 c-D_{1}^{\mathrm{r} 2} P_{1}^{\mathrm{r} 2} \alpha_{\mathrm{p}}^{2}-\beta^{2}\right)^{3}}
\end{array}\right.
$$

The impact of vulnerability on investments depends on the signs of $V D_{1}^{\mathrm{r} 2} P_{1}^{\mathrm{r} 2} \alpha_{\mathrm{p}}^{2}+2 D_{1}^{\mathrm{r}} P_{1}^{\mathrm{r}} \beta^{2}-8 c D_{1}^{\mathrm{r}} P_{1}^{\mathrm{r}}+4 V c-V \beta^{2}$ and $-D_{1}^{\mathrm{r} 2} P_{1}^{\mathrm{r} 2} \alpha_{\mathrm{p}}^{2}+2 V D_{1}^{\mathrm{r}} P_{1}^{\mathrm{r}} \alpha_{\mathrm{p}}^{2}-4 c+\beta^{2}$. For the seaport, when $0<\beta<\sqrt{4 c-V^{2} \alpha_{\mathrm{p}}^{2}}$, which means that the intensity of cooperative commercial relationships between the seaport and dry port is weak, $\partial I_{\mathrm{s}}^{\mathrm{p}} / \partial D_{1}^{\mathrm{r}} P_{1}^{\mathrm{r}}<0$ for all $D_{1}^{\mathrm{r}} P_{1}^{\mathrm{r}}$. When $\beta>\sqrt{4 c-V^{2} \alpha_{\mathrm{p}}^{2}}$, which means that the intensity of the cooperative commercial relationship is strong, if $0<D_{1}^{\mathrm{r}} P_{1}^{\mathrm{r}}<V-\sqrt{V^{2} \alpha_{\mathrm{p}}^{2}+\beta^{2}-4 c} / \alpha_{\mathrm{p}}, \quad \partial I_{\mathrm{s}}^{\mathrm{p}} / \partial D_{l}^{\mathrm{r}} P_{1}^{\mathrm{r}}<0, \quad$ and $\quad$ if $\quad V-$ $\sqrt{V^{2} \alpha_{\mathrm{p}}^{2}+\beta^{2}-4 c} / \alpha_{\mathrm{p}}<D_{1}^{\mathrm{r}} P_{1}^{\mathrm{r}}<V, \partial I_{\mathrm{s}}^{\mathrm{p}} / \partial D_{1}^{\mathrm{r}} P_{1}^{\mathrm{r}}>0$.

For the dry port, when $0<\beta<\sqrt{4 c-V^{2} \alpha_{\mathrm{p}}^{2}}$, if $0<D_{1}^{\mathrm{r}} P_{1}^{\mathrm{r}}<\left[-\sqrt{\left(4 c-\beta^{2}\right)\left(4 c-\beta^{2}-V^{2} \alpha_{\mathrm{p}}^{2}\right)}-\beta^{2}+4 c\right] /\left(V \alpha_{\mathrm{p}}^{2}\right), \partial I_{1}^{\mathrm{p}} / \partial D_{1}^{\mathrm{r}} P_{1}^{\mathrm{r}}>0$, and if $\left[-\sqrt{\left(4 c-\beta^{2}\right)\left(4 c-\beta^{2}-V^{2} \alpha_{\mathrm{p}}^{2}\right)}-\beta^{2}+4 c\right] /\left(V \alpha_{\mathrm{p}}^{2}\right)<D_{1}^{\mathrm{r}} P_{1}^{\mathrm{r}}<V, \partial I_{1}^{\mathrm{p}} / \partial D_{1}^{\mathrm{r}} P_{1}^{\mathrm{r}}<0$. When $\beta>\sqrt{4 c-V^{2} \alpha_{\mathrm{p}}^{2}}, \partial I_{1}^{\mathrm{p}} / \partial D_{1}^{\mathrm{r}} P_{1}^{\mathrm{r}}>0$ for all $D_{1}^{\mathrm{r}} P_{1}^{\mathrm{r}}$.

Therefore, the peer effect can be expressed as:

$$
\beta \sqrt{I_{\mathrm{s}}^{\mathrm{p}}}=\frac{\beta^{2}\left(V-D_{1}^{\mathrm{r}} P_{1}^{\mathrm{r}}\right)}{4 c-D_{1}^{\mathrm{r} 2} P_{1}^{\mathrm{r} 2} \alpha_{\mathrm{p}}^{2}-\beta^{2}}
$$


Clearly, the intensity of the cooperative relationship between the seaport and dry port affects positively the peer effect, and the impact of vulnerability on the peer effect can be expressed as:

$$
\frac{\partial \beta \sqrt{I_{\mathrm{s}}^{\mathrm{p}}}}{\partial D_{1}^{\mathrm{r}} P_{1}^{\mathrm{r}}}=\frac{\beta^{2}\left(V-D_{1}^{\mathrm{r}} P_{1}^{\mathrm{r}}\right)\left(-D_{1}^{\mathrm{r} 2} P_{1}^{\mathrm{r} 2} \alpha_{\mathrm{p}}^{2}+2 V D_{1}^{\mathrm{r}} P_{1}^{\mathrm{r}} \alpha_{\mathrm{p}}^{2}-4 c+\beta^{2}\right)}{\left(4 c-D_{1}^{\mathrm{r} 2} P_{1}^{\mathrm{r} 2} \alpha_{\mathrm{p}}^{2}-\beta^{2}\right)^{2}}
$$

where the sign of $\partial \beta \sqrt{I_{\mathrm{s}}^{\mathrm{p}}} / \partial D_{1}^{\mathrm{r}} P_{1}^{\mathrm{r}}$ is consistent with $\partial I_{\mathrm{s}}^{\mathrm{p}} / \partial D_{1}^{\mathrm{r}} P_{1}^{\mathrm{r}}$.

Lemma 1 In the vertically cooperative relationship, the vulnerability of the dry port to regular risk can suppress the peer effect, but a strong cooperative relationship between the seaport and dry port can overcome the impact of high vulnerability on the peer effect.

The impact of vulnerability on the peer effect depends on the sign of $-D_{1}^{\mathrm{r} 2} P_{1}^{\mathrm{r} 2} \alpha_{\mathrm{p}}^{2}+2 V D_{1}^{\mathrm{r}} P_{1}^{\mathrm{r}} \alpha_{\mathrm{p}}^{2}-4 c+\beta^{2}$, which is consistent with the impact of vulnerability on preventive investment in the seaport. Therefore, when $0<\beta<\sqrt{4 c-V^{2} \alpha_{\mathrm{p}}^{2}}$, it can be deduced that $\partial \beta \sqrt{I_{\mathrm{s}}^{\mathrm{p}}} / \partial D_{1}^{\mathrm{r}} P_{1}^{\mathrm{r}}<0$ for all $D_{1}^{\mathrm{r}} P_{1}^{\mathrm{r}}$, which means that as the vulnerability increases, the peer effect is weakened. When $\beta>\sqrt{4 c-V^{2} \alpha_{\mathrm{p}}^{2}}$, if $0<D_{1}^{\mathrm{r}} P_{1}^{\mathrm{r}}<V-\sqrt{V^{2} \alpha_{\mathrm{p}}^{2}+\beta^{2}-4 c} / \alpha_{\mathrm{p}}, \partial \beta \sqrt{I_{\mathrm{s}}^{\mathrm{p}}} / \partial D_{1}^{\mathrm{r}} P_{1}^{\mathrm{r}}<0, \quad$ if $V-\sqrt{V^{2} \alpha_{\mathrm{p}}^{2}+\beta^{2}-4 c} / \alpha_{\mathrm{p}}<D_{1}^{\mathrm{r}} P_{1}^{\mathrm{r}}<V, \quad \partial \beta \sqrt{I_{\mathrm{s}}^{\mathrm{p}}} / \partial D_{1}^{\mathrm{r}} P_{1}^{\mathrm{r}}>0$, which means that, when the seaport and dry port have a strong commercial relationship, only moderate vulnerability can effectively suppress the peer effect. In general, strong vertical cooperation between seaports and dry ports will increase the difference in the scale of their preventive investment.

Proposition 1 Stronger commercial relationships will enhance the peer effect, thereby increasing the difference in preventive investment size between the seaport and dry port, but moderate vulnerability $\left(D_{1}^{\mathrm{r}} P_{1}^{\mathrm{r}}=V-\sqrt{V^{2} \alpha_{\mathrm{p}}^{2}+\beta^{2}-4 c} / \alpha_{\mathrm{p}}\right)$ to regular risk would weaken this impact

Since the peer effect will inhibit the investment enthusiasm of cooperative ports, it will enlarge the difference in preventive investment between the seaport and dry port. When the commercial relationship between the two ports is strong, the active investment of one player is more likely to cause the other to hold back towards free-riding and reduce its investment, which increases the peer effect and widens the preventive investment size difference between the two ports. For example, if the horizontal cooperation relationship between the Chengdu dry port and the Shanghai seaport is very strong, the preventive investment of Chengdu can alleviate the regular risk of, say, congestion in the downstream Shanghai port, which will lead to a decrease in its preventive investment. 


\subsubsection{Case 2}

In this case, vertically cooperative seaport and dry port make adaptive investment decisions to address disruption risk. Similar to case 1, the net utility of the shipper can be expressed as $V-f_{1}-\mathrm{d} c-D_{1}^{\mathrm{d}} P_{1}^{\mathrm{d}}+\alpha_{\mathrm{a}} \sqrt{I_{1}^{\mathrm{a}}}-\beta \sqrt{I_{\mathrm{s}}^{\mathrm{a}}}$, the demand for dry port services is $Q=d^{*}=\left(V-f_{1}-D_{1}^{\mathrm{d}} P_{1}^{\mathrm{d}}+\alpha_{\mathrm{a}} \sqrt{I_{1}^{\mathrm{a}}}-\beta \sqrt{I_{\mathrm{s}}^{\mathrm{a}}}\right) / c$, and the total profit of the port is $\pi=f_{1} Q-I_{1}^{\mathrm{a}}-I_{\mathrm{s}}^{\mathrm{a}}$. By solving the first-order condition, $\partial \pi / \partial f_{1}=0$, the equilibrium THC can be derived as:

$$
f_{1}=\frac{V+\alpha_{\mathrm{a}} \sqrt{I_{1}^{\mathrm{a}}}-\beta \sqrt{I_{\mathrm{s}}^{\mathrm{a}}}-D_{1}^{\mathrm{d}} P_{1}^{\mathrm{d}}}{2} .
$$

Profit can then be expressed as:

$$
\pi=\frac{\left(V-D_{1}^{\mathrm{d}} P_{1}^{\mathrm{d}}+\alpha_{\mathrm{a}} \sqrt{I_{1}^{\mathrm{a}}}-\beta \sqrt{I_{\mathrm{s}}^{\mathrm{a}}}\right)^{2}}{4 c}-I_{1}^{\mathrm{a}}-I_{\mathrm{s}}^{\mathrm{a}} .
$$

Solving the first-order conditions, $\partial \pi / \partial I_{l}^{a}=0, \partial \pi / \partial I_{s}^{a}=0$, jointly derive the following preventive investments:

$$
\left\{\begin{array}{l}
I_{1}^{\mathrm{a}}=\frac{\alpha_{\mathrm{a}}^{2}\left(V-D_{1}^{\mathrm{d}} P_{1}^{\mathrm{d}}\right)^{2}}{\left(4 c-\alpha_{\mathrm{a}}^{2}-\beta^{2}\right)^{2}} \\
I_{\mathrm{s}}^{\mathrm{a}}=\frac{\beta^{2}\left(V-D_{1}^{\mathrm{d}} P_{1}^{\mathrm{d}}\right)^{2}}{\left(4 c-\alpha_{\mathrm{a}}^{2}-\beta^{2}\right)^{2}}
\end{array}\right.
$$

By substituting (13) into (11), we obtain $f_{1}=\left(2 c-\beta^{2}\right)\left(V-D_{1}^{\mathrm{d}} P_{1}^{\mathrm{d}}\right) /\left(4 c-\alpha_{\mathrm{a}}^{2}-\beta^{2}\right)$. In addition, we can determine how adaptive investment efficiency $\alpha_{\mathrm{a}}$, the cooperative relationship strength $\beta$, and unit distance transportation $\operatorname{cost} c$ affect the adaptive investment of the two ports. It can be easily seen that:

$$
\frac{\partial I_{1}^{\mathrm{a}}}{\partial D_{1}^{\mathrm{d}} P_{1}^{\mathrm{d}}}<0, \frac{\partial I_{1}^{\mathrm{a}}}{\partial \alpha_{\mathrm{a}}}>0, \frac{\partial I_{1}^{\mathrm{a}}}{\partial \beta}>0, \frac{\partial I_{1}^{\mathrm{a}}}{\partial c}<0, \frac{\partial I_{\mathrm{s}}^{\mathrm{a}}}{\partial D_{1}^{\mathrm{d}} P_{1}^{\mathrm{d}}}<0, \frac{\partial I_{\mathrm{s}}^{\mathrm{a}}}{\partial \alpha_{\mathrm{a}}}>0, \frac{\partial I_{\mathrm{s}}^{\mathrm{a}}}{\partial \beta}>0, \frac{\partial I_{\mathrm{s}}^{\mathrm{a}}}{\partial c}<0 .
$$

From these results, we can see that the changes in adaptive investments to address disruption risk are consistent with the preventive investments in case 1, except for vulnerability $D_{l}^{d} P_{l}^{d}$. Adaptive investments by both ports decrease, as vulnerability increases, regardless of the strength of the commercial relationship.

Similar to case 1 , the peer effect can be expressed as:

$$
\beta \sqrt{I_{\mathrm{s}}^{\mathrm{a}}}=\frac{\beta^{2}\left(V-D_{1}^{\mathrm{d}} P_{1}^{\mathrm{d}}\right)}{4 c-\alpha_{\mathrm{a}}^{2}-\beta^{2}}
$$


Lemma 2 In the vertical economic relationship, the vulnerability of dry ports to disruption risk can suppress the peer effect, and the greater the vulnerability is, the weaker the peer effect.

It is obvious that $\partial \beta \sqrt{I_{\mathrm{s}}^{\mathrm{p}}} / \partial \beta>0, \partial \beta \sqrt{I_{\mathrm{s}}^{\mathrm{p}}} / \partial D_{1}^{\mathrm{d}} P_{1}^{\mathrm{d}}<0$. Therefore, the strength of the cooperative relationship between the seaport and dry port affects positively the peer effect, while the vulnerability of the dry port to disruption risk affects negatively the peer effect. As mentioned above, $D_{i} P_{i}$ represents the vulnerability of ports to risks. Based on the characteristics of high probability and low damage of regular risks and low probability and high damage of disruption risk, it is reasonable to assume that $D_{i}^{\mathrm{d}} P_{i}^{\mathrm{d}} \approx D_{i}^{\mathrm{r}} P_{i}^{\mathrm{r}}$, which means that a given port is approximately equally vulnerable to regular risk and disruption risk. Therefore, by comparing (9) and (15), it can be deduced that, when $D_{i} P_{i}>\alpha_{\mathrm{a}} / \alpha_{\mathrm{p}}$, the peer effect of the adaptive investment process is smaller than that of the preventive investment process.

Proposition 2 In the vertically cooperative relationship, the peer effect has a greater impact on preventive investment than on adaptive investment, especially when vulnerability is relatively high.

The peer effect is also known as the free-riding problem. Compared with regular risk, investment in disruption risk mitigation is generally time-consuming and costly, which will inhibit the occurrence of free-riding to some extent. For example, due to the North Sea Flood of 1953, the Netherlands invested in infrastructure such as dams and storm surge barriers to protect the land, which took 44 years, until 1997, to complete. However, due to climate change and sea-level rise, the project committee proposed an additional 100 billion euros in investment to address these new challenges (Xiao et al. 2015). Besides, to cope with rising sea levels, frequent floods, and storm surges, Venice launched the mobile barriers (MOSE) project in 2003, which aims to protect the city from flooding by building movable sluices on the seafloor. Due to the size of the project, it was not actually put into use until October 2020 (Umgiesser 2020). Apparently, such risk cannot be completely resolved by free-riding. Moreover, when the strength of the cooperative relationship is high, greater vulnerability will enhance the peer effect of preventive investment and inhibit the peer effect of adaptive investment. Therefore, the peer effect has a greater impact on preventive investment, and the process of preventive investment is more prone to free-riding.

Proposition 3 For a vertical seaport-dry port system facing diverse risks, it is cost-efficient for ports with high vulnerability to choose adaptive investment and ports with low vulnerability to choose preventive investment.

According to (4) and (13), in the vertically cooperative relationship, the size of preventive and adaptive investments depends on $D_{i} P_{i} \alpha_{\mathrm{p}}$ and $\alpha_{\mathrm{a}}$. When $D_{i} P_{i}>\alpha_{\mathrm{a}} / \alpha_{\mathrm{p}}\left(D_{i} P_{i}<\alpha_{\mathrm{a}} / \alpha_{\mathrm{p}}\right)$, preventive investment is greater (smaller) than adaptive investment, which means that the cost of preventive investment for highly 
vulnerable ports is greater than that of adaptive investment when facing uncertain risks. Therefore, for the vertically cooperative relationship, if ports cannot determine the type of investment owing to the diversity of risks, it is better to choose adaptive investment for ports with high vulnerability and preventive investment for ports with low vulnerability. For example, the low-lying Rotterdam seaport is more vulnerable to climate-change-related risks such as the sea-level rise and responds to climate-change-related disruption risks through adaptive investment (the Delta Works) (Xiao et al. 2015), while the less vulnerable Baltimore seaport chooses to make preventive investments such as setting up berths based on the demand for ultra-large cargo ships to ease congestion (Fan et al. 2012).

\subsection{Investment decisions under asymmetric horizontal competition}

In this section, the commercial relationship between the seaport and dry port authorities is horizontal competition. As competitive seaports and dry ports now compete for shippers in the common hinterland, they both want to gain a competitive advantage through investment, which leads to a competition effect between them. Therefore, the competition effect positively affects the investment enthusiasm of ports (Wang and Zhang 2018). Moreover, unlike previous studies, which assumed that the two seaports show the same vulnerability to risk (Wang and Zhang 2018; Randrianarisoa and Zhang 2019), this study adopts the more realistic assumption of asymmetric vulnerability. This means that seaport and dry port authorities have an asymmetric horizontal competition relationship. Therefore, the preventive and adaptive investment decisions of the seaport and dry port authorities in the face of regular risk and disruption risk under the asymmetric horizontal competition are analyzed in this part.

\subsubsection{Case 3}

In this case, competing seaport and dry port authorities make preventive investment decisions in response to regular risk. A shipper located at point $d$ can choose the seaport or dry port to provide services. The utility of choosing the dry port can be expressed as $U_{1}=V-f_{1}-\mathrm{d} c-D_{1}^{\mathrm{r}} P_{1}^{\mathrm{r}}+D_{1}^{\mathrm{r}} P_{1}^{\mathrm{r}} \alpha_{\mathrm{p}} \sqrt{I_{1}^{\mathrm{p}}}+\beta \sqrt{I_{\mathrm{s}}^{\mathrm{p}}}$, and the utility of choosing the seaport can be expressed as $U_{\mathrm{s}}=V-f_{\mathrm{s}}-(1-\mathrm{d}) c-D_{\mathrm{s}}^{\mathrm{r}} P_{\mathrm{s}}^{\mathrm{r}}+D_{\mathrm{s}}^{\mathrm{r}} P_{\mathrm{s}}^{\mathrm{r}} \alpha_{\mathrm{p}} \sqrt{I_{\mathrm{s}}^{\mathrm{p}}}+\beta \sqrt{I_{1}^{\mathrm{p}}}$. Therefore, the location $d^{*}$ where shippers are indifferent between using either port can be derived from (16).

$$
d^{*}=\frac{1}{2}+\frac{f_{\mathrm{s}}-f_{1}-\left(D_{\mathrm{s}}^{\mathrm{r}} P_{\mathrm{s}}^{\mathrm{r}} \alpha_{\mathrm{p}}-\beta\right) \sqrt{I_{\mathrm{s}}^{\mathrm{p}}}+\left(D_{1}^{\mathrm{r}} P_{1}^{\mathrm{r}} \alpha_{\mathrm{p}}-\beta\right) \sqrt{I_{1}^{\mathrm{p}}}+\left(D_{\mathrm{s}}^{\mathrm{r}} P_{\mathrm{s}}^{\mathrm{r}}-D_{1}^{\mathrm{r}} P_{1}^{\mathrm{r}}\right)}{2 c} .
$$

Therefore, the demand for the seaport and dry port services can be expressed as: 


$$
\left\{\begin{array}{l}
Q_{1}=\frac{1}{2}+\frac{f_{\mathrm{s}}-f_{1}-\left(D_{\mathrm{s}}^{\mathrm{r}} P_{\mathrm{s}}^{\mathrm{r}} \alpha_{\mathrm{p}}-\beta\right) \sqrt{I_{\mathrm{s}}^{\mathrm{p}}}+\left(D_{1}^{\mathrm{r}} P_{1}^{\mathrm{r}} \alpha_{\mathrm{p}}-\beta\right) \sqrt{I_{1}^{\mathrm{p}}}+\left(D_{\mathrm{s}}^{\mathrm{r}} P_{\mathrm{s}}^{\mathrm{r}}-D_{1}^{\mathrm{r}} P_{1}^{\mathrm{r}}\right)}{2 c} \\
Q_{\mathrm{s}}=\frac{1}{2}-\frac{f_{\mathrm{s}}-f_{1}-\left(D_{\mathrm{s}}^{\mathrm{r}} P_{\mathrm{s}}^{\mathrm{r}} \alpha_{\mathrm{p}}-\beta\right) \sqrt{I_{\mathrm{s}}^{\mathrm{p}}}+\left(D_{1}^{\mathrm{r}} P_{1}^{\mathrm{r}} \alpha_{\mathrm{p}}-\beta\right) \sqrt{I_{1}^{\mathrm{p}}}+\left(D_{\mathrm{s}}^{\mathrm{r}} P_{\mathrm{s}}^{\mathrm{r}}-D_{1}^{\mathrm{r}} P_{1}^{\mathrm{r}}\right)}{2 c}
\end{array} .\right.
$$

In the operational stage, the preventive investments of the PAs have been completed. The profit of the seaport authority is $\pi_{\mathrm{s}}=f_{\mathrm{s}} Q_{\mathrm{s}}-I_{\mathrm{s}}^{\mathrm{p}}$, and the profit of the dry port authority is $\pi_{1}=f_{1} Q_{1}-I_{1}^{\mathrm{p}}$. At this stage, the PAs decide to charge shippers THC $f_{\mathrm{s}}$ and $f_{1}$ to maximize profits. Solving the first-order conditions, $\partial \pi_{\mathrm{s}} / \partial f_{\mathrm{s}}=0$, $\partial \pi_{1} / \partial f_{1}=0$, jointly derives the following THC:

$$
\left\{\begin{array}{l}
f_{1}=\frac{3 c-\left(D_{\mathrm{s}}^{\mathrm{r}} P_{\mathrm{s}}^{\mathrm{r}} \alpha_{\mathrm{p}}+\beta\right) \sqrt{I_{\mathrm{s}}^{\mathrm{p}}}+\left(D_{1}^{\mathrm{r}} P_{1}^{\mathrm{r}} \alpha_{\mathrm{p}}+\beta\right) \sqrt{I_{1}^{\mathrm{p}}}-\left(D_{1}^{\mathrm{r}} P_{1}^{\mathrm{r}}-D_{\mathrm{s}}^{\mathrm{r}} P_{\mathrm{s}}^{\mathrm{r}}\right)}{3} \\
f_{\mathrm{s}}=\frac{3 c+\left(D_{\mathrm{s}}^{\mathrm{r}} P_{\mathrm{s}}^{\mathrm{r}} \alpha_{\mathrm{p}}+\beta\right) \sqrt{I_{\mathrm{s}}^{\mathrm{p}}}-\left(D_{1}^{\mathrm{r}} P_{1}^{\mathrm{r}} \alpha_{\mathrm{p}}+\beta\right) \sqrt{I_{1}^{\mathrm{p}}}+\left(D_{1}^{\mathrm{r}} P_{1}^{\mathrm{r}}-D_{\mathrm{s}}^{\mathrm{r}} P_{\mathrm{s}}^{\mathrm{r}}\right)}{3}
\end{array} .\right.
$$

In the strategic investment stage, it is assumed that seaport and dry port authorities simultaneously determine preventive investments to maximize profits. Substituting $f_{l}, f_{s}$ into $\pi_{l}, \pi_{s}$, and solving the first-order conditions, $\partial \pi_{l} / \partial I_{l}^{p}=0, \partial \pi_{s} / \partial I_{s}^{p}=0$, jointly derives the following preventive investments of the dry port and seaport:

$$
\left\{\begin{array}{l}
I_{1}^{\mathrm{p}}=\frac{\left(D_{1}^{\mathrm{r}} P_{1}^{\mathrm{r}} \alpha_{\mathrm{p}}-\beta\right)^{2}\left[9 c-\left(D_{\mathrm{s}}^{\mathrm{r}} P_{\mathrm{s}}^{\mathrm{r}} \alpha_{\mathrm{p}}-\beta\right)^{2}-3\left(D_{1}^{\mathrm{r}} P_{1}^{\mathrm{r}}-D_{\mathrm{s}}^{\mathrm{r}} P_{\mathrm{s}}^{\mathrm{r}}\right)\right]^{2}}{\left[54 c-3\left(D_{\mathrm{s}}^{\mathrm{r}} P_{\mathrm{s}}^{\mathrm{r}} \alpha_{\mathrm{p}}-\beta\right)^{2}-3\left(D_{1}^{\mathrm{r}} P_{1}^{\mathrm{r}} \alpha_{\mathrm{p}}-\beta\right)^{2}\right]^{2}} \\
I_{\mathrm{s}}^{\mathrm{p}}=\frac{\left(D_{\mathrm{s}}^{\mathrm{r}} P_{\mathrm{s}}^{\mathrm{r}} \alpha_{\mathrm{p}}-\beta\right)^{2}\left[9 c-\left(D_{1}^{\mathrm{r}} P_{1}^{\mathrm{r}} \alpha_{\mathrm{p}}-\beta\right)^{2}+3\left(D_{1}^{\mathrm{r}} P_{1}^{\mathrm{r}}-D_{\mathrm{s}}^{\mathrm{r}} P_{\mathrm{s}}^{\mathrm{r}}\right)\right]^{2}}{\left[54 c-3\left(D_{\mathrm{s}}^{\mathrm{r}} P_{\mathrm{s}}^{\mathrm{r}} \alpha_{\mathrm{p}}-\beta\right)^{2}-3\left(D_{1}^{\mathrm{r}} P_{1}^{\mathrm{r}} \alpha_{\mathrm{p}}-\beta\right)^{2}\right]^{2}}
\end{array} .\right.
$$

To obtain clearer economic insights from (19), a simulation is conducted to better understand the changes in preventive investments by the seaport and dry port. Based on previous studies (Stern 2007; Wang et al. 2020), we set the vulnerability $D_{i}^{\mathrm{r}} P_{i}^{\mathrm{r}}$ and the commercial relationship (intensity of competition) $\beta$ to $[0,1]$, and let $c=0.5$. In addition, the robustness of the results is verified by making $\alpha_{\mathrm{p}}=0.3,0.6,0.9$, where different $\alpha_{\mathrm{p}}$ values reflect different investment efficiencies. The results are shown in Figs. 4 and 5, where the smaller the preventive investment is, the darker the color.

As seen from Figs. 4 and 5, the three results obtained with different investment efficiencies $\left(\alpha_{\mathrm{p}}=0.3,0.6,0.9\right)$ almost overlap in each figure, which proves the robustness of the results. According to Fig. 4a and Fig. 5a, the greater the vulnerability of the seaport (dry port) to regular risk, the greater the preventive investment in the dry port (seaport) regardless of the intensity of competition. Figures $4 \mathrm{~b}$ and $5 \mathrm{~b}$ show that, when the intensity of competition is weak, the greater the vulnerability to regular risk of the dry port (seaport) is, the greater the preventive investment of the dry port (seaport). When the intensity of competition is high, the preventive 


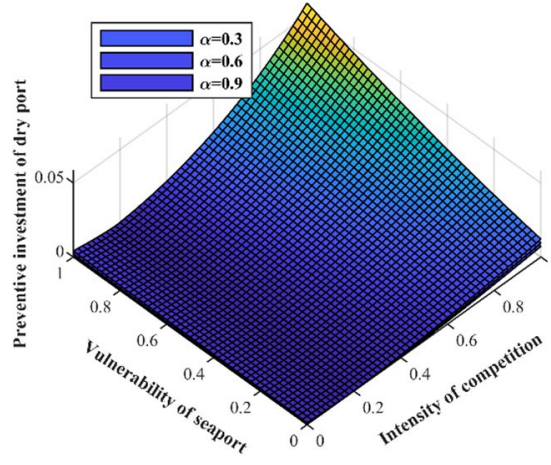

(a) Changes in the vulnerability of the seaport

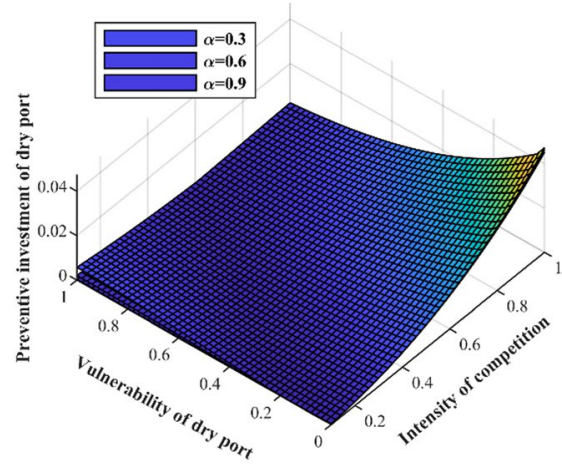

(b) Changes in the vulnerability of the dry port

Fig. 4 Impact of vulnerability change on preventive investment by the dry port

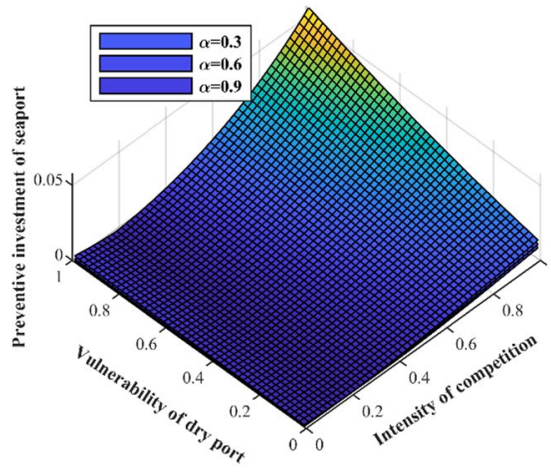

(a) Changes in the vulnerability of the dry port

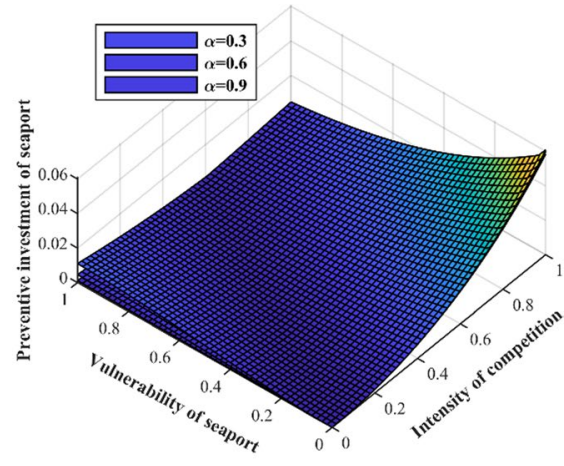

(b) Changes in the vulnerability of the seaport

Fig. 5 Impact of vulnerability change on preventive investment by the seaport

investment in the dry port (seaport) decreases with the increasing vulnerability of the dry port (seaport).

Therefore, in the asymmetric horizontal seaport-dry port system, a lower vulnerability of the seaport (dry port) to regular risk and a higher vulnerability of a dry port (seaport) will exacerbate the competition effect when the competitive intensity is high. In general, a lower competitive intensity will suppress the competition effect, which is intuitive. However, for a higher competitive intensity, the competitive effect is affected by the vulnerability of both the seaport and dry port to regular risk. For example, a low vulnerability of the dry port (Fig. 4b) and a high vulnerability of the seaport (Fig. 4a) will expand the competitive advantage of the port, thereby enhancing the competitive effect by increasing preventive investment.

Moreover, the asymmetric horizontal competition will widen the difference in preventive investment size between the seaport and dry port, and a lower intensity of competition will alleviate this difference. The asymmetry is mainly manifested 
by the asymmetric vulnerability of the seaport and dry port to risks. According to (19), when $D_{1}^{\mathrm{r}} P_{1}^{\mathrm{r}}=D_{\mathrm{s}}^{\mathrm{r}} P_{\mathrm{s}}^{\mathrm{r}}$, the seaport and dry port will make equal preventive investments, which is consistent with the system consisting of two seaports. However, as noted above, an inland dry port is more sensitive to regular risk such as congestion, and the existence of dry ports can alleviate seaport congestion, so it is assumed that $D_{1}^{\mathrm{r}} P_{1}^{\mathrm{r}}>D_{\mathrm{s}}^{\mathrm{r}} P_{\mathrm{s}}^{\mathrm{r}}$. Therefore, according to Lemma 3, in the case of high competitive intensity, a lower vulnerability of the seaport and a higher vulnerability of the dry port will intensify the competition effect faced by the seaport and thus increase its investment. In contrast, it will inhibit the competition effect faced by the dry port and reduce its investment, thereby widening the difference in preventive investment size between the seaport and dry port. Lower competitive intensity will moderate the competition effect, which will ease the differences in preventive investment between the seaport and dry port.

\subsubsection{Case 4}

In this case, competing seaport and dry port authorities make adaptive investment decisions against regular risk. Similar to case 3, the utility of choosing the dry port can be expressed as $U_{1}=V-f_{1}-\mathrm{d} c-D_{1}^{\mathrm{d}} P_{1}^{\mathrm{d}}+\alpha_{\mathrm{a}} \sqrt{I_{1}^{\mathrm{a}}}+\beta \sqrt{I_{\mathrm{s}}^{\mathrm{a}}}$, and the shippers' utility of choosing the seaport can be expressed as $U_{\mathrm{s}}=V-f_{\mathrm{s}}-(1-\mathrm{d}) c-D_{\mathrm{s}}^{\mathrm{d}} P_{\mathrm{s}}^{\mathrm{d}}+\alpha_{\mathrm{a}} \sqrt{I_{\mathrm{s}}^{\mathrm{a}}}+\beta \sqrt{I_{1}^{\mathrm{a}}}$. The marginal location of shippers $d^{*}$ can be derived as:

$$
d^{*}=\frac{1}{2}+\frac{f_{\mathrm{s}}-f_{1}+\left(\alpha_{\mathrm{a}}-\beta\right)\left(\sqrt{I_{1}^{\mathrm{a}}}-\sqrt{I_{\mathrm{s}}^{\mathrm{a}}}\right)+\left(D_{\mathrm{s}}^{\mathrm{d}} P_{\mathrm{s}}^{\mathrm{d}}-D_{1}^{\mathrm{d}} P_{1}^{\mathrm{d}}\right)}{2 c} .
$$

Therefore, the demand for the seaport and dry port services can be expressed as:

$$
\left\{\begin{array}{l}
Q_{1}=\frac{1}{2}+\frac{f_{\mathrm{s}}-f_{1}+\left(\alpha_{\mathrm{a}}-\beta\right)\left(\sqrt{I_{1}^{\mathrm{a}}}-\sqrt{I_{\mathrm{s}}^{\mathrm{a}}}\right)+\left(D_{\mathrm{s}}^{\mathrm{d}} P_{\mathrm{s}}^{\mathrm{d}}-D_{1}^{\mathrm{d}} P_{1}^{\mathrm{d}}\right)}{2 c} \\
Q_{\mathrm{s}}=\frac{1}{2}-\frac{f_{\mathrm{s}}-f_{1}+\left(\alpha_{\mathrm{a}}-\beta\right)\left(\sqrt{I_{1}^{\mathrm{a}}}-\sqrt{I_{\mathrm{s}}^{\mathrm{a}}}\right)+\left(D_{\mathrm{s}}^{\mathrm{d}} P_{\mathrm{s}}^{\mathrm{d}}-D_{1}^{\mathrm{d}} P_{1}^{\mathrm{d}}\right)}{2 c}
\end{array} .\right.
$$

At the operational stage, the adaptive investments of PAs have been completed. The profit of the seaport authority is $\pi_{\mathrm{s}}=f_{\mathrm{s}} Q_{\mathrm{s}}-I_{\mathrm{s}}^{\mathrm{a}}$, and the profit of the dry port authority is $\pi_{1}=f_{1} Q_{1}-I_{1}^{\mathrm{a}}$. Solving the first-order conditions, $\partial \pi_{\mathrm{s}} / \partial f_{\mathrm{s}}=0$, $\partial \pi_{1} / \partial f_{1}=0$, jointly derives the following THC:

$$
\left\{\begin{array}{l}
f_{\mathrm{l}}=\frac{3 c+\left(\alpha_{\mathrm{a}}-\beta\right)\left(\sqrt{I_{1}^{\mathrm{a}}}-\sqrt{I_{\mathrm{s}}^{\mathrm{a}}}\right)+\left(D_{\mathrm{s}}^{\mathrm{d}} P_{\mathrm{s}}^{\mathrm{d}}-D_{1}^{\mathrm{d}} P_{1}^{\mathrm{d}}\right)}{3} \\
f_{\mathrm{s}}=\frac{3 c-\left(\alpha_{\mathrm{a}}-\beta\right)\left(\sqrt{I_{1}^{\mathrm{a}}}-\sqrt{I_{\mathrm{s}}^{\mathrm{a}}}\right)-\left(D_{\mathrm{s}}^{\mathrm{d}} P_{\mathrm{s}}^{\mathrm{d}}-D_{1}^{\mathrm{d}} P_{1}^{\mathrm{d}}\right)}{3}
\end{array}\right.
$$


Substituting $f_{\mathrm{l}}, f_{\mathrm{s}}$ into $\pi_{\mathrm{l}}, \pi_{\mathrm{s}}$, and solving the first-order conditions, $\partial \pi_{\mathrm{l}} / \partial I_{1}^{\mathrm{a}}=0$, $\partial \pi_{s} / \partial I_{s}^{a}=0$, jointly derives the following adaptive investments:

$$
\left\{\begin{array}{l}
I_{1}^{\mathrm{a}}=\frac{\left(\alpha_{\mathrm{a}}-\beta\right)^{2}\left[9 c-\left(\alpha_{\mathrm{a}}-\beta\right)^{2}-3\left(D_{1}^{\mathrm{d}} P_{1}^{\mathrm{d}}-D_{\mathrm{s}}^{\mathrm{d}} P_{\mathrm{s}}^{\mathrm{d}}\right)\right]^{2}}{\left[54 c-6\left(\alpha_{\mathrm{a}}-\beta\right)^{2}\right]^{2}} \\
I_{\mathrm{s}}^{\mathrm{a}}=\frac{\left(\alpha_{\mathrm{a}}-\beta\right)^{2}\left[9 c-\left(\alpha_{\mathrm{a}}-\beta\right)^{2}+3\left(D_{1}^{\mathrm{d}} P_{1}^{\mathrm{d}}-D_{\mathrm{s}}^{\mathrm{d}} P_{\mathrm{s}}^{\mathrm{d}}\right)\right]^{2}}{\left[54 c-6\left(\alpha_{\mathrm{a}}-\beta\right)^{2}\right]^{2}}
\end{array}\right.
$$

By substituting (23) into the THC function and profit function, we can obtain:

$$
\begin{gathered}
\left\{\begin{array}{l}
f_{1}=\frac{c\left[9 c-\left(\alpha_{\mathrm{a}}-\beta\right)^{2}-3\left(D_{1}^{\mathrm{d}} P_{1}^{\mathrm{d}}-D_{\mathrm{s}}^{\mathrm{d}} P_{\mathrm{s}}^{\mathrm{d}}\right)\right]}{9 c-\left(\alpha_{\mathrm{a}}-\beta\right)^{2}} \\
f_{\mathrm{s}}=\frac{c\left[9 c-\left(\alpha_{\mathrm{a}}-\beta\right)^{2}+3\left(D_{1}^{\mathrm{d}} P_{1}^{\mathrm{d}}-D_{\mathrm{s}}^{\mathrm{d}} P_{\mathrm{s}}^{\mathrm{d}}\right)\right]}{9 c-\left(\alpha_{\mathrm{a}}-\beta\right)^{2}}
\end{array}\right. \\
\left\{\begin{array}{l}
\pi_{1}=\frac{\left[18 c-\left(\alpha_{\mathrm{a}}-\beta\right)^{2}\right]\left[9 c-\left(\alpha_{\mathrm{a}}-\beta\right)^{2}-3\left(D_{1}^{\mathrm{d}} P_{1}^{\mathrm{d}}-D_{\mathrm{s}}^{\mathrm{d}} P_{\mathrm{s}}^{\mathrm{d}}\right)\right]^{2}}{36\left[9 c-\left(\alpha_{\mathrm{a}}-\beta\right)^{2}\right]^{2}} \\
\pi_{\mathrm{s}}=\frac{\left[18 c-\left(\alpha_{\mathrm{a}}-\beta\right)^{2}\right]\left[9 c-\left(\alpha_{\mathrm{a}}-\beta\right)^{2}+3\left(D_{1}^{\mathrm{d}} P_{1}^{\mathrm{d}}-D_{\mathrm{s}}^{\mathrm{d}} P_{\mathrm{s}}^{\mathrm{d}}\right)\right]^{2}}{36\left[9 c-\left(\alpha_{\mathrm{a}}-\beta\right)^{2}\right]^{2}}
\end{array}\right.
\end{gathered}
$$

Proposition 4 In the horizontally competitive economic relation, the profit and THC of the dry port authority are greater than those of the seaport authority, and the asymmetry will widen this difference.

Due to its geographic location, the seaport is more sensitive to climate-changerelated disruption risk, so it is reasonable to assume that the seaport is more vulnerable to disruption risk than the dry port, namely $D_{1}^{\mathrm{d}} P_{1}^{\mathrm{d}}<D_{\mathrm{s}}^{\mathrm{d}} P_{\mathrm{s}}^{\mathrm{d}}$. Therefore, it can be derived that the THC and profit of the dry port are less than those of the seaport $\left(f_{l}>f_{s}\right.$, $\pi_{1}>\pi_{\mathrm{s}}$ ) according to (24) and (25). Moreover, the asymmetry is mainly manifested by the asymmetric vulnerability of the seaport and dry port. Obviously, the greater the asymmetry $\left(D_{1}^{\mathrm{d}} P_{1}^{\mathrm{d}}-D_{\mathrm{s}}^{\mathrm{d}} P_{\mathrm{s}}^{\mathrm{d}}\right)$ between the seaport and dry port, the greater the difference in THC and profit between the seaport and the dry port.

Similar to case 3 , the following comparative statics are calculated to depict the impact of vulnerabilities on adaptive investments.

$$
\frac{\partial I_{1}^{\mathrm{a}}}{D_{1}^{\mathrm{d}} P_{1}^{\mathrm{d}}}<0, \frac{\partial I_{1}^{\mathrm{a}}}{D_{\mathrm{s}}^{\mathrm{d}} P_{\mathrm{s}}^{\mathrm{d}}}>0, \frac{\partial I_{\mathrm{s}}^{\mathrm{a}}}{D_{\mathrm{s}}^{\mathrm{d}} P_{\mathrm{s}}^{\mathrm{d}}}<0, \frac{\partial I_{\mathrm{s}}^{\mathrm{a}}}{D_{1}^{\mathrm{d}} P_{1}^{\mathrm{d}}}>0 .
$$


Proposition 5 In the horizontal seaport-dry port system, the low vulnerability of a port and the high vulnerability of the competing port to disruption risk can promote the competition effect regardless of the intensity of competition.

According to (26), the low vulnerability of a port and the high vulnerability of the competing port will promote the adaptive investment of the port in the horizontal competition, thereby enhancing the competition effect. Therefore, in a horizontal seaport-dry port system, the adaptive investment decisions of ports are not only related to their vulnerability to disruption risk but also influenced by the vulnerability of competing ports.

Proposition 6 For a horizontal seaport-dry port system facing uncertain risks, it is cost-efficient to choose adaptive investments for ports with higher vulnerability $\left(D_{i}^{\mathrm{r}} P_{i}^{\mathrm{r}}>\alpha_{\mathrm{a}} / \alpha_{\mathrm{p}}\right)$ but lower vulnerability $\left(D_{j}^{\mathrm{r}} P_{j}^{\mathrm{r}}<\alpha_{\mathrm{a}} / \alpha_{\mathrm{p}}\right)$ for competitors and preventive investment for ports with lower vulnerability but higher vulnerability for competitors.

Similar to the vertically cooperative relationship, the size of preventive and adaptive investments in the seaport and dry port depends on $D_{i}^{\mathrm{r}} P_{i}^{\mathrm{r}} \alpha_{\mathrm{p}}$ and $\alpha_{\mathrm{a}}$ in the horizontal competition according to (19) and (23). When $D_{i}^{\mathrm{r}} P_{i}^{\mathrm{r}}>\alpha_{\mathrm{a}} / \alpha_{\mathrm{p}}$ and $D_{j}^{\mathrm{r}} P_{j}^{\mathrm{r}}<\alpha_{\mathrm{a}} / \alpha_{\mathrm{p}}$, the preventive investment of port $i$ is greater than the adaptive investment, where $D_{j}^{\mathrm{r}} P_{j}^{\mathrm{r}}$ is the vulnerability of the competing port. Therefore, under this circumstance, for ports facing uncertain risks, choosing preventive investment can achieve profit maximization with less investment. Unlike the vertically cooperative relationship, the investment is not only related to the vulnerability of the port but is also affected by the vulnerability of competing ports in the system. Therefore, when port authorities make preventive investment decisions, players under vertically cooperative economic relations should consider not only their own vulnerability but also that of others. This illustrates the importance of sharing relevant information such as vulnerability among players in a vertically cooperative economic relationship.

\section{Conclusions}

This research proposes a two-stage game to simultaneously study the preventive and adaptive investments of seaport and dry port authorities under different risks and economic relationships among the two ports. This study contributes to the extant literature in the following ways: (i) it identifies the preventive and adaptive investment of the vertically cooperative and horizontally competing seaport-dry port systems against regular and disruption risks; (ii) it incorporates in the model the interaction effects between seaports and dry ports due to vertical cooperation and horizontal competition; (iii) it examines the impact of the interaction effect, asymmetry, and the diversity of risks in the seaport-dry port system on preventive and adaptive investments. 
The results of this study emphasize the importance of considering vertically cooperative and horizontally competing economic relations and diverse risks in preventive and adaptive investment decisions. Our findings provide managerial insights into the decision-making and policy-making efforts of seaport and dry port authorities. First, in the process of investment decision-making by seaport and dry port authorities, we show that it is necessary to identify the main type of risks facing ports, to determine whether to make preventive investments, to address regular risk, or adaptive investments to deal with disruption risk. Under resource constraints, PAs need to choose targeted investments based on the types of risks they face. For example, the low-lying Rotterdam seaport is vulnerable to climate-change-related risks, such as the rise of sea level, and responds to such risks through adaptive investments (the Delta Works) (Xiao et al. 2015). Facing the demand for ultra-large containerships, Baltimore seaport has made preventive investments, such as setting up berths to cope with the risk of congestion in daily operations (Fan et al. 2012).

Second, although the pursuit of closer cooperation between the seaport and the dry port, in the vertically cooperative relationship, can strengthen the connection between the seaport and its hinterland, it is not always advisable to blindly pursue intensive vertical cooperation. For example, although the vertical cooperation between the Chengdu dry port and the Shanghai seaport can advance the Yangtze River Economic Belt and strengthen the links between the seaport and its hinterland, excessive vertical integration of the two ports, located in the upper and lower reaches of the Yangtze River Basin, will enable Shanghai to use the infrastructure investment of the Chengdu dry port to relieve congestion. Free-rider decisions such as this may need careful consideration in the further development of "port systems."

Third, in view of the complex economic relationships between ports, when making investment decisions, players must not only consider their own situation but also make adjustments based on the situation of others. In reality, many ports take the risk-mitigating infrastructure investment as the means to enhance their competitiveness, but the ports that cannot effectively control the risk will lose the corresponding competitive advantage. For example, the Port of Kobe in Japan failed to effectively adapt to the Great Hanshin Earthquake in 1995 and suffered heavy losses after the earthquake. The 2-year recovery period deprived it of most of its transshipment cargo to competing Asian ports, as well as its competitive advantage for a long time to come (Chang 2000).

This study identifies some avenues for future research. First, to analyze the important characteristics of cooperative and competitive markets, we consider a two-player game in the seaport-dry port system, which can shed light on multiplayer games. Therefore, the practical market structure of one seaport corresponding to multiple dry ports deserves to be pursued in future studies. Second, it is assumed that PAs can only make one of the preventive or adaptive investments owing to resource constraints, which, in reality, does not apply to all seaports and dry ports. Some PAs may carry out both preventive investment and adaptive investment at the same time. Therefore, for seaports and dry ports that face multiple risks, whether there is a tradeoff in investment decisions that enables ports to achieve both the optimal preventive investment to address regular risk and the optimal adaptive investment to address disruption risk needs further exploration. 
Acknowledgements The authors are grateful for the time and effort devoted by the Editor-in-Chief and the reviewers to improve this work. This work was supported by the National Natural Science Foundation of China (Grant Nos. 71732006 and 71390330), and the National Key Research and Development Program of China (Grant No. 2019YFB1704100).

\section{References}

Agency, X. N. 2021. 2020 China-Europe Express Train Breaks Through Ten Thousand Trains. Xinhua Finance.

Asadabadi, A., and E. Miller-Hooks. 2018. Co-opetition in enhancing global port network resiliency: A multi-leader, common-follower game theoretic approach. Transportation Research Part B 108: 281-298.

Becker, A.H., P. Matson, M. Fischer, and M.D. Mastrandrea. 2015. Towards seaport resilience for climate change adaptation: Stakeholder perceptions of hurricane impacts in Gulfport (MS) and Providence (RI). Progress in Planning 99: 1-49.

Berdica, K. 2002. An introduction to road vulnerability: What has been done, is done and should be done. Transport Policy 9: 117-127.

Bloomberg. 2011, December 1. How to Fix World Transportation. Bloomberg Businessweek.

Cao, X., and J.S.L. Lam. 2019. Simulation-based severe weather-induced container terminal economic loss estimation. Maritime Policy and Management 46: 92-116.

Chang, S.E. 2000. Disasters and transport systems: Loss, recovery and competition at the Port of Kobe after the 1995 earthquake. Journal of Transport Geography 8: 53-65.

Chen, H., K. Cullinane, and N. Liu. 2017. Developing a model for measuring the resilience of a porthinterland container transportation network. Transportation Research Part E 97: 282-301.

Chen, H., J.S.L. Lam, and N. Liu. 2018. Strategic investment in enhancing port-hinterland container transportation network resilience: A network game theory approach. Transportation Research Part B 111: 83-112.

Fan, L., W.W. Wilson, and B. Dahl. 2012. Congestion, port expansion and spatial competition for US container imports. Transportation Research Part E 48: 1121-1136.

Gong, Z., and N. Liu. 2020. Mitigative and adaptive investments for natural disasters and labor strikes in a seaport-dry port inland logistics network. Maritime Policy \& Management 47: 92-108.

Gou, X., and J.S.L. Lam. 2019. Risk analysis of marine cargoes and major port disruptions. Maritime Economics \& Logistics 21: 497-523.

Grauberger, W., and A. Kimms. 2016. Revenue management under horizontal and vertical competition within airline alliances. Omega 59: 228-237.

Iannone, F. 2012. The private and social cost efficiency of port hinterland container distribution through a regional logistics system. Transportation Research Part A 46: 1424-1448.

Irannezhad, E., C.G. Prato, and M. Hickman. 2018. The effect of cooperation among shipping lines on transport costs and pollutant emissions. Transportation Research Part D 65: 312-323.

Jackson, M.O., and Y. Zenou. 2015. Games on Networks. Handbook of Game Theory with Economic Applications 4: 95-163.

Jeevan, J., S.-L. Chen, and S. Cahoon. 2019. The impact of dry port operations on container seaports competitiveness. Maritime Policy \& Management 46: 4-23.

Kaplan, S., and B.J. Garrick. 1981. On the quantitative definition of risk. Risk Analysis 1: 11-27.

Kavirathna, C.A., T. Kawasaki, and S. Hanaoka. 2019. Intra-port coopetition under different combinations of terminal ownership. Transportation Research Part E 128: 132-148.

Khaslavskaya, A., and V. Roso. 2020. Dry ports: Research outcomes, trends, and future implications. Maritime Economics and Logistics 22: 265-292.

Kleindorfer, P.R., and G.H. Saad. 2005. Managing disruption risks in supply chains. Production and Operations Management 14: 53-68.

Lam, J.S.L., C. Liu, and X. Gou. 2017. Cyclone risk mapping for critical coastal infrastructure: Cases of East Asian seaports. Ocean \& Coastal Management 141: 43-54.

Lam, J.S.L., and S. Su. 2015. Disruption risks and mitigation strategies: An analysis of Asian ports. Maritime Policy \& Management 42: 415-435. 
Lam, J.S.L., and W.Y. Yap. 2011. Container port competition and complementarity in supply chain systems: Evidence from the Pearl River Delta. Maritime Economics \& Logistics 13: 102-120.

Lee, C.Y., and D.P. Song. 2017. Ocean container transport in global supply chains: Overview and research opportunities. Transportation Research Part B 95: 442-474.

Li, C., X. Qi, and D. Song. 2016. Real-time schedule recovery in liner shipping service with regular uncertainties and disruption events. Transportation Research Part B 93: 762-788.

Liu, N., Z. Gong, and X. Xiao. 2018. Disaster prevention and strategic investment for multiple ports in a region: Cooperation or not. Maritime Policy and Management 45: 585-603.

Qiu, X., J.S.L. Lam, and G.Q. Huang. 2015. A bilevel storage pricing model for outbound containers in a dry port system. Transportation Research Part E 73: 65-83.

Randrianarisoa, L.M., K. Wang, and A. Zhang. 2020. Insights from recent economic modeling on port adaptation to climate change effects. Maritime Transport and Regional Sustainability. https://doi. org/10.1016/B978-0-12-819134-7.00004-6.

Randrianarisoa, L.M., and A. Zhang. 2019. Adaptation to climate change effects and competition between ports: Invest now or later? Transportation Research Part B 123: 279-322.

Roso, V., J. Woxenius, and K. Lumsden. 2009. The dry port concept: Connecting container seaports with the hinterland. Journal of Transport Geography 17: 338-345.

Song, D.P., A. Lyons, D. Li, and H. Sharifi. 2016. Modeling port competition from a transport chain perspective. Transportation Research Part E 87: 75-96.

Tan, Z., Q. Meng, F. Wang, and H.B. Kuang. 2018. Strategic integration of the inland port and shipping service for the ocean carrier. Transportation Research Part E 110: 90-109.

Umgiesser, G. 2020. The impact of operating the mobile barriers in Venice (MOSE) under climate change. Journal for Nature Conservation 54: 125783.

UNCTAD. 2018. 50 Years of Review of Maritime Transport, 1968-2018: Reflecting on the past, exploring the future. Page 50 Years of Review of Maritime Transport, 1968-2018: Reflecting on the past, exploring the future.

UNCTAD. 2020. Review of Maritime Transport 2020. Page New York: United Nations.

Wang, K., H. Yang, and A. Zhang. 2020. Seaport adaptation to climate change-related disasters: Terminal operator market structure and inter-and intra-port coopetition. Spatial Economic Analysis 15: 311-335.

Wang, K., and A. Zhang. 2018. Climate change, natural disasters and adaptation investments: Inter- and intra-port competition and cooperation. Transportation Research Part B 117: 158-189.

Wei, H., Z. Sheng, and P.T.W. Lee. 2018. The role of dry port in hub-and-spoke network under Belt and Road Initiative. Maritime Policy and Management 45: 370-387.

Xiao, Y.B., X. Fu, A.K.Y. Ng, and A. Zhang. 2015. Port investments on coastal and marine disasters prevention: Economic modeling and implications. Transportation Research Part B 78: 202-221.

Zhang, Q., W. Wang, Y. Peng, J. Zhang, and Z. Guo. 2018. A game-theoretical model of port competition on intermodal network and pricing strategy. Transportation Research Part E 114: 19-39.

Zhang, Y., and J.S.L. Lam. 2015. Estimating the economic losses of port disruption due to extreme wind events. Ocean \& Coastal Management 116: 300-310.

Zheng, S., and M. Luo. 2021. Competition or cooperation? Ports' strategies and welfare analysis facing shipping alliances. Transportation Research Part E 153: 102429.

Publisher's Note Springer Nature remains neutral with regard to jurisdictional claims in published maps and institutional affiliations. 